\title{
Study on Technical Feasibility of High-energy loads Participating in Respond to Shave Power Grid Peak with Large Scale New Energy Base
}

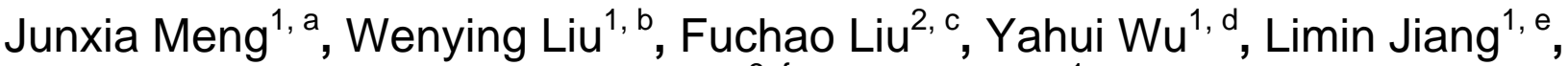 \\ Huaguang $\mathrm{Yan}^{3, \mathrm{f}}$, Guixiong $\mathrm{He}^{1, \mathrm{~g}}$, \\ ${ }^{1}$ The State Key Laboratory of Power Grid Safety and Energy Conservation (China Electric Power \\ Research Institute), Haidian District, Beijing \\ ${ }^{2}$ North China electric power university, Changping District, Beijing \\ ${ }^{3}$ State Grid Gansu Electric Power Company, Lanzhou, Gansu Province \\ ajxmeng@epri.sgcc.com.cn, bliuwenyingls@sina.com, \\ cliufc8127@sina.com, ${ }^{d}$ wuyahui1018@163.com, ${ }^{\mathrm{e} j i a n g l m @ e p r i . s g c c . c o m . c n, ~}$ \\ 'hgyan@epri.sgcc.com.cn, ${ }^{9}$ heguixiong@epri.sgcc.com.cn
}

\begin{abstract}
Keywords: high-energy loads, adjustable characteristics, new energy power consumption, technical feasibility.

Abstract. Under the research background that large scale new energy base located in the Hexi corridor area, in view of typical high-energy loads in Gansu province, such as silicon carbide, aluminum electrolytic, focus on key electrical equipment in production processes, adjustable features of high-energy loads as well as affecting factors are analyzed. Meanwhile, companies' constraint conditions to participate in demand response were also under consideration. Every effort is want to demonstrate an argument whether high-energy loads participating in respond to meet power grid demand with large scale new energy base can be carried out or not. By means of analyzing structure of power grid and output characteristics of new energy base located in Hexi area, as well adjustable capacity of conventional power generators, regulation strategy of high-energy loads on multi time scale is studied, and give some advice on engineering practice in the conclusion.
\end{abstract}

\section{Introduction}

"Cluster Development" and "Long Distance Transmission" have become main modes of China's new energy development, such as wind power. "Three North Region", which means north-east of china, north china and north-west of china, has abundant wind resource and the most grid connected electricity in China, while it has the highest rate abandoned wind power ratio. New energy industry in the Jiajiu area located in Hexi corridor of Gansu province is developing rapidly, but also be faced with problems such as insufficient delivery capacity, and diseconomy to transmit electricity for a long-distance massively. It is an excellent scheme for consuming new energy power by local high-energy loads. Moreover, the scheme is a new path to introduce demand response mechanisms to address the new energy consumption problem [1]. Whether the high-energy loads that accounts for about $74 \%$ of local electricity consumption have characteristics of removing peak or shifting peak to respond new energy power fluctuation becomes the key point to consume new energy power by coordinated operation among loads, grids and generations, while reducing loss derived from long distance transmission.

\section{Production Processes and Load Regulation Characteristics of High-energy Loads.}

According to Gansu provincial planning, a number of high energy consumption enterprises will be relocated in the Hexi corridor area [2]. Most of these enterprises take electricity from 330/750 kV high voltage DC power directly. Only taken into account high-energy loads with high capacity, which access to $750 \mathrm{KV}$ high voltage DC power grid of the Hexi corridor, At the end of 2014, silicon carbide load access to grid at the Dunhuang $750 \mathrm{KV}$ substation as cluster point of wind power and photoelectric, had reached up to 1.3 million kilowatts. Besides, both aluminum electrolytic load and 
iron alloy load access to grid at the Jiuquan $750 \mathrm{KV}$ substation as another cluster point, had reached up to 3.1 million kilowatts. Total number is about 4.4 million kilowatts $[3,4,5]$.

Typical Industrial Production Technologies and Major Electrical Equipment. The proportion of energy consumption cost may reach to thirty percentage in whole production value produced by high-energy consumptive industries. From the aspect of procession, manufacturing process of high-energy consumptive productions were applying energy on processed objects (such as ores) to change their physical forms, sintering, melting, electrolysis, synthesis, for example. Then, high-energy consumptive products were formed by separation and extraction.

Electrolytic aluminum, ferroalloy, silicon carbide, cement and calcium carbide are typical high-energy consumptive industries in Gansu province. High-energy loads (Some companies have captive power plants) have regulative capacity to some extent. For example, silicon carbide is formed by smelting in electric resistance furnace at very high temperature, which use quartz sand, petroleum coke (or coal), wood as raw material. The chemical reaction is as follows:

$$
S_{i} O_{2}+3 C_{1700^{\sim} 200{ }^{\circ} \mathrm{C}} S_{i} C+2 C O \uparrow
$$
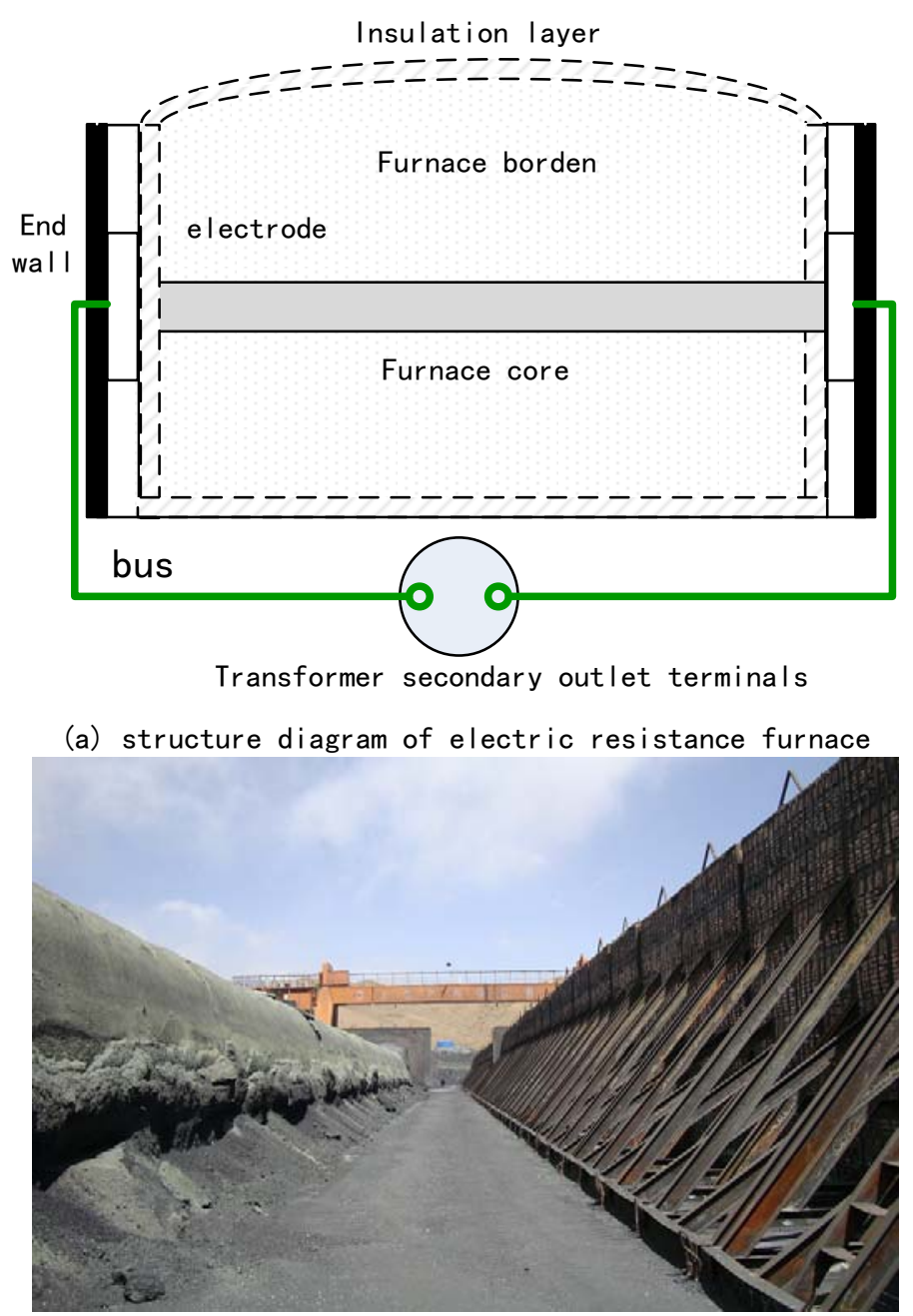

(b) production site of silicon carbide

Fig.1. structure diagram of electric resistance furnace and production site

High-temperature calcination, grading, crushing and screening are major processing technics throughout the whole smelting process of silicon carbide. Major energy-consuming equipments are resistance furnaces and motors. For instance, as the rated power of electric resistance furnace is about $12500 \mathrm{kVA}$, the maximum furnace load can reached $12000 \mathrm{~kW}$, and thermal insulation load (minimum furnace load) is range from 800 to $1000 \mathrm{~kW}$. Then, adjustable load capacity reaching up to more than $90 \%$ of its rated capacity, silicon carbide can avoid peak load period of power grid to be produced, as 
Fig. 2 below. Power supply may be interrupted in case of emergency in a short time. It will has a little effect on production if only power-off time not more than 20 to 30 minutes.

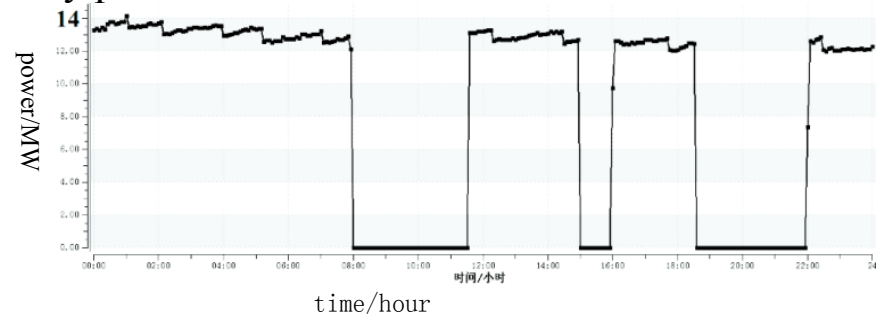

Fig.2. load curve of a feeder connected a special transformer on 19/10/2014

The fundamental motivation of high-energy consumption enterprises participating in respond to shave power grid peak is cost saving. The current peak and valley tariff policy in Gansu province is shown in Table.1. As Fig.2 showing, silicon carbide enterprise save the cost by means of adjusting load according to electricity price varying, which may be nearly shut down at high price period and fully produced at low price [6].

Table.1 Peak-valley tariff in Gansu province

\begin{tabular}{|c|c|c|c|c|c|c|}
\hline $\begin{array}{c}\text { classificatio } \\
\mathrm{n} \text { of } \\
\text { electricity } \\
\text { consumptio } \\
\mathrm{n}\end{array}$ & $\begin{array}{c}\text { voltage } \\
\text { level }\end{array}$ & peak & flat & valley & $\begin{array}{c}\text { maximum demand } \\
(¥ / \mathrm{kW} . \mathrm{M})\end{array}$ & $\begin{array}{c}\text { Transformer capacity } \\
\text { (¥/kVA.M) }\end{array}$ \\
\hline $\begin{array}{c}\text { industrial } \\
\text { bulk }\end{array}$ & $1-10 \mathrm{kV}$ & 0.7091 & 0.4806 & 0.2520 & 33 & 22 \\
\cline { 2 - 7 } & $35 \mathrm{kV}$ & 0.6941 & 0.4706 & 0.2470 & 33 & 22 \\
\cline { 2 - 7 } \\
$\begin{array}{c}\text { electricity } \\
\text { consumptio } \\
\mathrm{n}\end{array}$ & $110 \mathrm{kV}$ & 0.6791 & 0.4606 & 0.2420 & 33 & 22 \\
\cline { 2 - 7 } & $220 \mathrm{kV}$ & 0.6716 & 0.4556 & 0.2395 & 33 & 22 \\
\hline
\end{tabular}

Study on Adjustable Characteristics of High-energy Loads. The adjustable/interruptible characteristics of high-energy loads is mainly determined by production process requirements and performance of power consumption equipment. The relationship between production craft sequences and maximum adjustable/interruptible capacity (potential) of high-energy loads is shown in Fig.3.

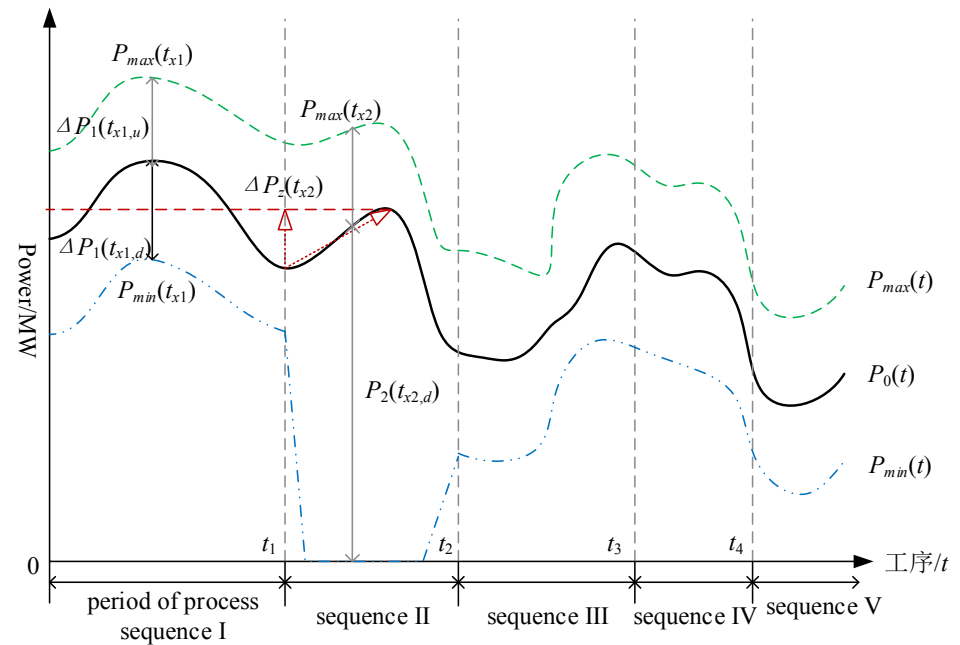

Fig.3. Relationship between the production craft sequence and maximum adjustable/interruptible Capacity

As shown in Fig.3, P0(t) represents natural process load curve when high-energy loads do not participate in respond to shifting peak of power grid. $P_{\max }(t)$ represents maximum regulated capacity of high-energy loads to increase load of power grid at time $\mathrm{t}$ in a period of process sequence. $P_{\min }(t)$ represents minimum regulated capacity of high-energy loads to reduce load of power grid at $t$ in a period of process sequence. The process crafts are divided into several sequences according to type of output and operational requirements, such as process sequence I, process sequence II in Fig.3. Adjustable potential of high-energy consumptive enterprise is different from process sequences. For example, high-energy loads can be increased to maximum capacity $P_{\max }\left(t_{x 1}\right)$, or be reduce to minimum 
capacity $P_{\min }\left(t_{x 1}\right)$ in period of process sequence I. Bidirectional adjustable potential capacity is $\Delta P_{1}\left(t_{x 1, u}\right)$ and $\Delta P_{1}\left(t_{x 1, d}\right), t_{x 1} \in\left[0, t_{1}\right]$. From process sequence II on, process load has a natural increment $\Delta P_{z}\left(t_{x 2}\right)$, which has no relevance to shifting peak and only determined by certain process craft, $t_{x 2} \in\left\lfloor t_{1}, t_{2}\right\rfloor . \Delta P_{z}\left(t_{x 2}\right)$ may not be take into consideration alone, just analyzing adjustable capacity of high-energy loads $P_{\max }\left(t_{x 2}\right)$, because peak shaving effect is combination of these two. That is, addition of $\Delta P_{z}\left(t_{x 2}\right)$ and $P_{\max }\left(t_{x 2}\right)$ is actual effect, but $\Delta P_{z}\left(t_{x 2}\right)$ is not adjustable.

As different craft requirements between process sequence I and process sequence II, adjustable loads can be completely shaved in process sequence II if the enterprise interrupting production. Therefore, compared with high-energy loads and traditional thermal power unit, the complexity of high-energy loads is that peak shaving performance parameters are related to process sequence, because different process sequences have different craft requirements, and use different electrical equipment. Relationship model should be established between process sequence and load regulating capacity, for having an insight into accurately quantitative regulation capacity in the whole process sequences of high-energy loads. From the perspective of power grid dispatching, the potential adjustable capacity of high-energy loads is $\Delta P(t) \in\left[P_{\min }(t)-P_{0}(t), P_{\max }(t)-P_{0}(t)\right]$. Regulation performance at a certain time determined by these three key parameters, which are adjustable capacity $\Delta P(t)$, adjust time and ramp rate. Values of these parameters are confirmed by experiences or a number of tests, and the relationship model is established among performance of adjustable/interrupted load and process sequence, equipment performance and yield.

Constraints of High-energy loads Enterprises Participate in Demand Response. The results of the field survey shows that most of existing high-energy consumptive enterprises are difficult to respond to volatility and randomness of new energy sources, such as wind power. By means of transforming production equipment and improving process craft, and improving the management ability of flexible production at the same time. Then, these enterprises may have abilities to use new energy power. High-energy loads participating in respond to shave peak must meet the following conditions:

(1) have adjustable / interruptible flexible loads to some extent;

(2) production equipment (probably by means of transformation) can adapt to limit values of voltage and current;

(3) have little influences on production safety, product quality and yield.

A. Restriction and Optimization of the Production Craft.

For example, there are many important parameters in electrolysis process that should be stabled within a certain range in Aluminum electrolytic process, such as voltage, current and temperature. When companies take part in wind power consumption, several parameters may vary violently if they do not take any necessary measurements, and their regular production will be disrupted. Therefore, these companies need improve processing technique and update equipment, and establish basic prediction model and optimized control model of each process sequence in Aluminum smelting process. On the one hand, they can achieve optimized control in each process sequence, scientific decision-making and accurate fault diagnosis as well. On the other hand, modeling and optimization methods about complex industrial production process should be discussed.

The major issue should be considered is to improve productivity efficiency of aluminum electrolytic process, and main optimized parameters are current and power consumption. Variables that affect electrolysis effect are anode-cathode-distance, alumina concentration, molar ratio, electrolyte and its temperature, height of liquid aluminum. The target would be production efficiency is maximum, while having maximum current efficiency and minimum power consumption. Under the constraint of material balance and energy balance, the optimal design model expresses as following:

$\left\{\begin{array}{l}\max \eta=f_{1}\left(d, r, c, T, l_{1}, l_{2}\right) \\ \min W=f_{2}\left(d, r, c, T, l_{1}, l_{2}\right)\end{array}\right.$

where, $\quad \eta-$-current efficiency of electrolytic cells;

$W-$ DC power consumption of electrolytic cells; 
$d$ - - anode-cathode-distance;

c-—alumina concentration;

$r$ - molar ratio;

T-— temperature of electrolyte;

$l_{1}$ - - height of electrolyte;

$l_{2}$ - - height of liquid aluminum.

$f_{1}$ and $f_{2}$ show relationships between variables that affect electrolysis effect and current efficiency, as well as power consumption respectively. Therefore, automatic controlled electrolysis equipment should be designed and applied to, in order to adjust material balance and energy balance in real time according to current of electrolytic cell, and to achieve deeply coupling aluminum electrolysis process with wind power consumption.

B. Analysis on Tolerance of High-energy loads for Electricity Prices.

Energy cost accounts for $20 \% \sim 70 \%$ of total product cost in high-energy consumptive enterprises. Product cost may rise by $10 \% \sim 14 \%$ when electricity price moving up $20 \%$. Common products of these enterprises belong to basic productive materials, there has little performance difference from similar type products. Therefore, electricity price fluctuation will have an important impact on their benefits, these enterprises are sensitive to electricity price. It will be an effective mean to encourage high-energy consumptive enterprises to participate in shaving load peak of power grid with large scale new energy.

Products of a high-energy consumptive enterprise priced $\mathrm{Y} ¥ /$ ton during a certain period. The proportion of electricity cost in total production cost is $\alpha$, and electricity cost of unit product is $\mathrm{X} ¥ /$ ton. Then, the production cost of unit product is expressed as following:

$$
L=\frac{X}{\alpha} \quad(20 \% \leq \alpha \leq 70 \%)
$$

Earnings of unit production is

$$
S=Y-L
$$

The tolerance electricity price is that the enterprise can afford when earnings of unit production approaching to zero. Given impact on the enterprise producing activity, when benefit from lower tariff and shaving peak are more than benefit from unit production of the enterprise do not participate in shaving peak, the enterprise has enthusiasm to participate in shaving peak.

\section{Output Characteristics of New Energy and Peak Shaving Capacity in Hexi Corridor}

By the end of 2013, installed capacity of wind power reached to 7.02 million kilowatts and solar energy reached to 4.29 million kilowatts in Hexi area. By the end of the "Twelfth Five-year Plan", installed capacity of wind power accounted for $52.5 \%$ in total installed power, which became the largest power source. Besides, solar energy accounted for $22.56 \%$ and became the second large power source. According to prediction of load and power developing, load only accounts for $26 \%$ of total installed power in Hexi area. Therefore, most of power need export to consume thorough power line.

Power grid of Hexi area connects with main grid of Gansu province thorough double-circuit line that voltage level are $330 \mathrm{kV}$ and $750 \mathrm{kV}$, and connects with grids of Xinjiang autonomous region thorough four-circuit line that voltage level is $750 \mathrm{kV}$, and with grid of Qinghai province thorough double-circuit line that voltage level is $750 \mathrm{kV}$. The main mission of tie-lines is export electricity, which connects Hexi power grid with transmission grid of Gansu province, and with transmission grid of Qinghai. transmission grid of Hexi area not only take the task of exporting local surplus electricity, but also transferring power from Xinjiang autonomous region to other places. Transmission capacity on the Jiuquan side is 3300MW. Transmission capacity of Shazhou substation located in Gansu province is about 2000MW, which connects grid of Xinjiang autonomous region with 
grid of Qinghai province through double-circuit line that voltage level is $750 \mathrm{kV}$. Both Jiuquan and Shazhou side have maximum transmission capacity that is $5300 \mathrm{MW}$, including $2000 \mathrm{MW}$ to transfer power from Xinjiang autonomous region. Before HVDC transmission project was completed in Jiuquan, power grid of Hexi area can't meet the requirements of local new energy development $[7,8]$. Peak Shaving Capacity of Conventional Generators. Installed capacity of thermal generators account for about $17.8 \%$ of total in Hexi area, as well as installed capacity of hydro turbines account for $7.09 \%$. From the perspective of developing trend of conventional generators, both thermal power and hydropower will be reduced gradually. More than half thermal power units are heat supply units which have very limited peak shaving capacity, and the maximum capacity during non-heating period is $6195 \mathrm{MW}$, as well as 4630MW during heating period. Most of hydropower plants are run-of-river type which nearly has no regulated storage capacity. Maximum peak regulated capacity of hydro turbines in the province is $2640 \mathrm{MW}$. Above all, local peak regulated capacity is so poor that can't meet requirements of developing large-scale new energy power [9]. Therefore, hydropower and thermal powers should be mixed with new energy power for long distance transmitting on one hand, on the other hand a new way that flexible loads participating in response to meet grid demand should be discussed. The latter can keep power flow in a high voltage transmission lines fluctuating within a certain range, while improve local consumptive capacity of new energy power significantly.

Output Characteristics of the New Energy Base in Jiuquan. Taking wind power as an example, we analyze output characteristics of wind farm group in Jiuquan area. Moment of inertia in wind turbine can restrain output fluctuations of active power at sub-second time scale effectively. Besides, distributed geographic location of wind turbines lower rate of wind farm output change at a few minutes time scale. Rate a single wind farm output change does not exceed $10 \%$ of whole wind farm rated output per minute based on statistics. Overall, decentralized wind turbines and wind farms are able to reduce output correlation at grid-connected node, but the complementary output mainly happens in sub-hour time scale. Furthermore, distributed geographic location of wind farm group lower rate of its output change in a few hours. Rate of the whole base output change in Jiuquan is about from $0.69 \%$ to $1.80 \%$ per minute.

A. Daily Output Characteristics of Wind Power.

Using weighted average value of wind power output every moment in same season to analyze typical output curve of every season, and we discovered a laws that output of the base located in Jiuquan is smaller during the day and bigger at night all the year round, shown as Fig.4. Output is smaller during 8:00 18:00, and bigger from 18:00 to 8:00 in next day. From the point of maximum values occurs, except for the maximum value appearing during 6:00 8: 00 in autumn, another three seasons appear during 0:00-3: 00, which is valley time of load curve. It has obvious anti-peaking characteristics.

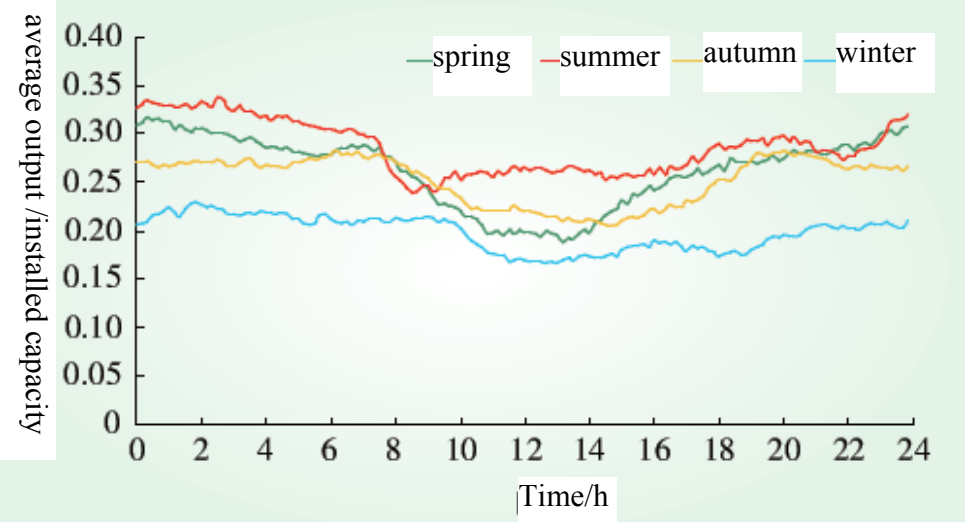

Fig.4. Typical daily output characteristics of the base in Jiuquan every season

B. Monthly Output Characteristics of Wind Power.

Average monthly output ratio is vary from 0.17 to 0.31 , and the maximum value appears in July and the minimum value appears in January. Overall, Output of the base in Jiuquan presents a laws that it becomes bigger in spring and summer, while becoming smaller in autumn and winter, as shown in Fig.5. 


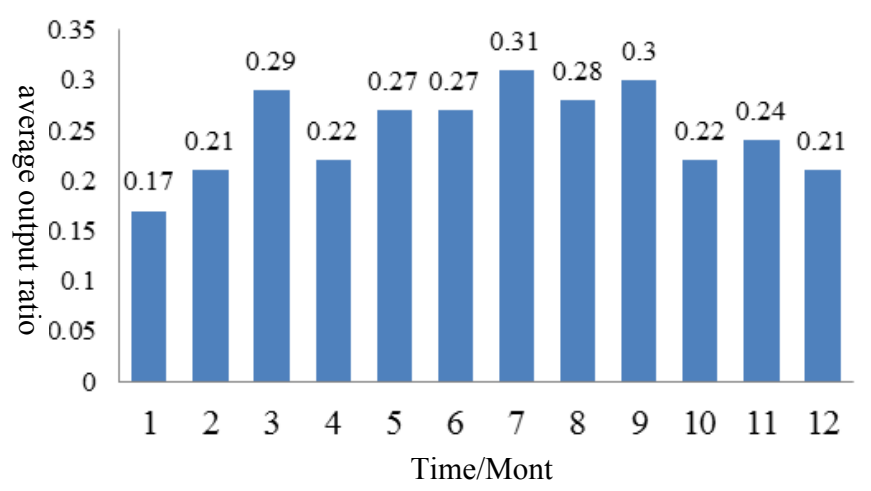

Fig.5. Average monthly output ratio of the wind power base in 2012

\section{Technical Approach to Resolve Problems Derived from High-energy loads Participating in Respond to Shave Peak of Power grid with Large Scale New Energy Base}

Now, High-energy consumptive enterprises have characteristics of continuous and stable production generally, for their production equipment, process technology and production planning are designed under the premise of stable power supplying. Therefore, they are lack of interaction with power supply, and workers here are lack of interactive experience in operation, and productions loads have insufficient response capacity by themselves. In addition, technical level of automatic production adopted by most enterprises is very low to some extent and many production processes need operate or adjust manually depend on experience of workers. Quality of products will be affected easily when process craft parameters change drastically. Furthermore, High-energy consumptive enterprises are maximize profit-oriented, their productions prices and production status are affected by supply and demand of market during different period, so they do not put consuming wind power in the first place on their own.

This situation can't exclude impossibility of high-energy loads have ability to respond fluctuation and randomness of wind power output. It was reported that diversified strategic approaches were applied to utilize large-scale wind power in China, which points out wind power should be deeply coupled with aluminum electrolytic, hydrogen created by electrolysis of water, seawater desalination, and coal chemical industry, etc. by means of necessary technical innovation and integration in a number of new-built green heavy chemical industry park. It has made a major breakthrough in operation laws and internal coupling mechanisms of creating hydrogen by electrolysis of water, intelligent control system of circulation and speed in dynamic balance system between wind power output and electrolytic cells, and an efficient and multi-level seawater desalination systems running at low-temperature [10]. There is an obvious positive correlation between cement production and seasonal output of wind power in Gansu province. Generally, from November to March of next year is demand off-season affected by market supply and demand, and production loads may be reduced less than a third of that in demand season. All these provides a good condition for high-energy consumptive enterprises to utilize wind power locally.

Peak-shaving Strategy of High-energy loads Response to New Energy Output. According to the power consumption characteristics of high-energy consumption industry, process load can be divided into transferable loads, continuous adjustable loads and interruptible loads. They can provide peak-shaving capacity at different time scale respectively. Transferable loads and captive power plants dispatched by power grid shave peak at long time scale. They need to make dispatching strategies day ahead, and modify these strategies daily. Continuous adjustable loads usually undertake the task at a short time scale. Finally, Interruptible loads can be regarded as a positive reserve capacity for power system, which only work in case of power shortage. All of them need coordinate with conventional generators to shave peak loads properly.

In a hybrid system coupled high-energy loads, conventional generators and renewable energy together, high-energy loads can be regarded as "virtual power", key regulatory modes are smooth 
power output mode, tracking planned output mode and peak shaving model. Under tracking planned output model, actual output power of the hybrid system will be as close to planned output as possible by adjusting high-energy loads when conventional generators do not meet the requirements of peak-shaving. The model is the better way to solve existing problems about new energy consumption in Hexi area currently.

Planned output curve of the system may be predictive power curve based on wind speed prediction, or may be curve worked out according to assessed local load quantity. Generally, the following dispatching strategies should abide by:

(1) It is advocated that wind power should be consumed as much as possible, namely, wind power with priority to connect the grid;

(2) It is still can't meet demand of the grid even though wind power being utilized as much as possible, high-energy loads should be adjusted to meet the demand if adjustable capacity of them is sufficient;

(3) If planned output curve already exceeding adjustable range of the hybrid system, it is correct to adjust output of the system as close to the planned one as possible, while actual output needn't equal to it exactly.

Both coupling wind power with key power consumption equipment of aluminum electrolytic, or hydrogen creation by electrolyzing water, etc. and predicting and tracking output of wind power is to adjust power consumption characteristics of high-energy loads better, then would be response to fluctuant output of renewable energy power as best possible. Control cycle of main production equipment may be set to five minutes, which is synchronized with dispatching commend given to wind farm. Fig. 6 shows a cluster control system of certain wind farm, which accepts dispatching commend every five minutes. Then the farm adjusts its power output according to the dispatching commend.

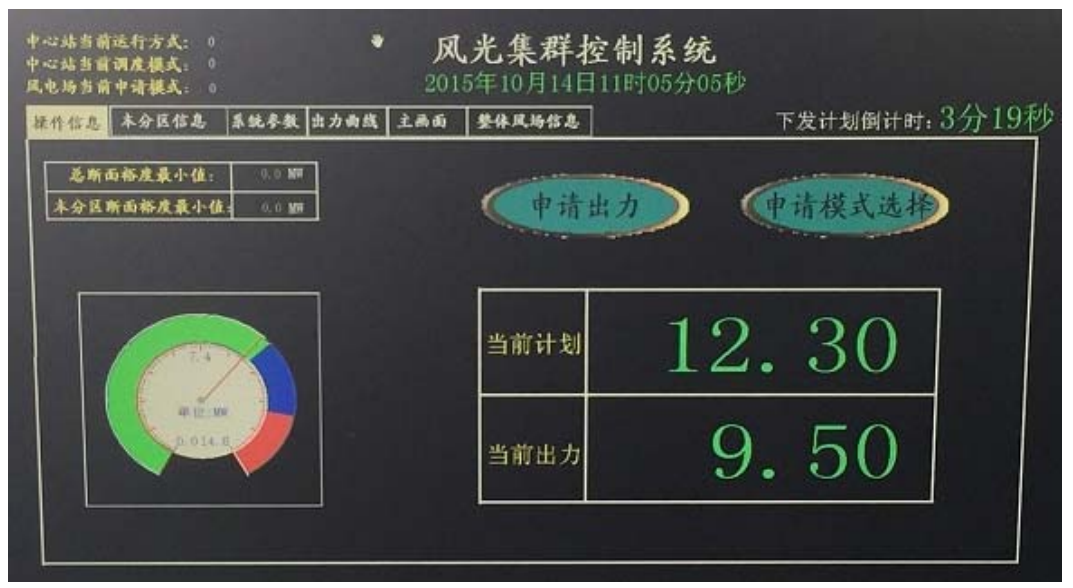

Fig.6. wind/solar cluster control system of a wind farm in Hexi area

With regard to transferable loads, high-energy consumptive enterprises should draw up a plan day ahead, then modify the plan by way of adjusting flexible interruptible loads within a day. Fig. 7 shows actual output data of wind power for nine consecutive days in Hexi area. If transferable loads (such as loads of silicon carbide processing) can be shifted in different days, it should transfer production loads in december12th, 15th, and 16th to 17th and 18th. Partial load can be interrupted in the 14th afternoon if there needs continuous adjustment within a day. 


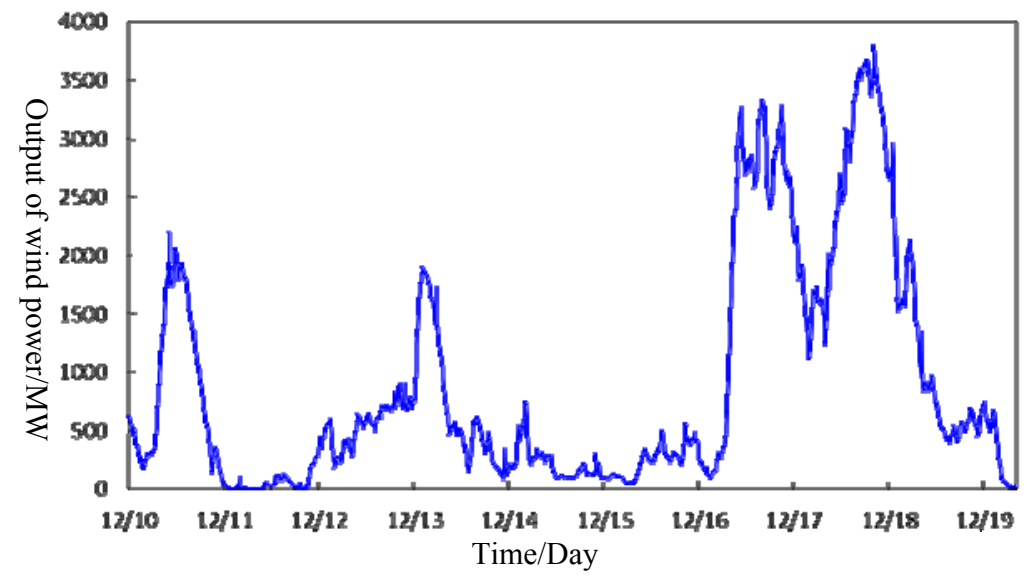

Fig.7 Output curve of wind power from 11th to 19th in December, 2013

Electricity consumption monitoring system of high-energy loads carries on monitoring electricity consumption of high-energy loads online, which helps these enterprises to be aware of their energy consumption in production processing in real time. And let power grid dispatching to master potential capacity of adjustable flexible loads of these high-energy consumptive enterprises. The system realizes acquisition in real time, and monitors status of operation and control of high-energy loads on online, and assesses adjustable capability of high-energy loads dynamically, and works as information interface between monitoring subsystem and control subsystem of high-energy loads, and issues/receives dispatching commands of sub-station for high-energy loads, etc. Shown in Fig.8.

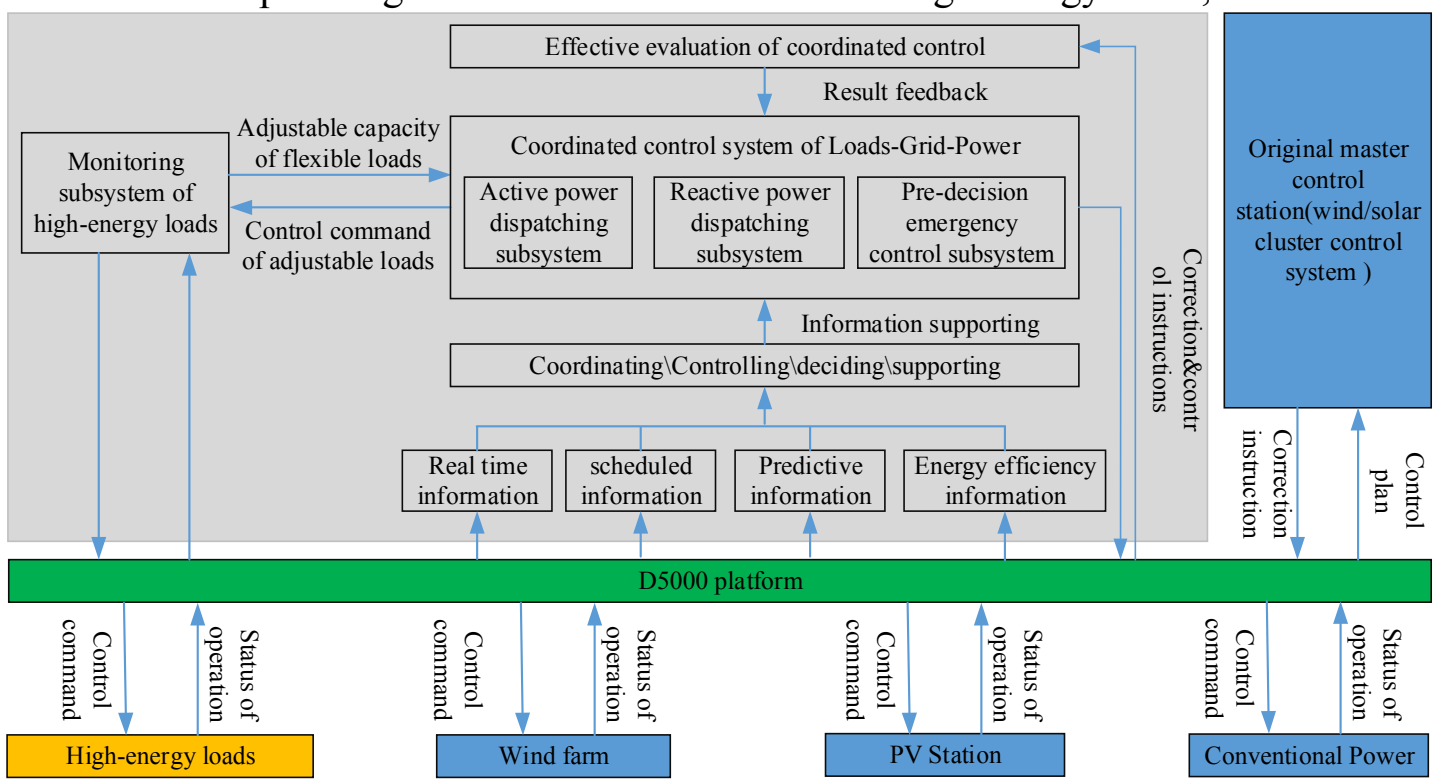

Fig.8. $R \& D$ schematic diagram of monitoring subsystem of high-energy loads

Power Supply Mode of High-energy loads. Grid-connected wind power is difficult to exceed $8 \sim 10$ percent of total power transmission without responding to fluctuation of wind power by thermal power, hydropower, etc. With the proportion of grid-connected wind power growing, It will inevitably have a difficult for wind power to connect the grid. According to electricity consumption characteristics of high-energy consumptive enterprises, partial wind farm connect to high-voltage distribution network nearby (such as $110 \mathrm{kV}$ ), then supply power to high-energy consumptive consumers directly. For the wind power no longer connecting to $750 \mathrm{kV}$ transmission network, which can effectively relieve congestion of the transmission network. On the other hand, power lines dedicated to high-energy consumptive consumers in industrial parks may be built up [11], as Fig.9. This mode is one of effective solutions to consume wind power through "source-load" interaction, and broken through current consumptive mode, which it is necessary that wind power should be connected to the grid for utilization. 


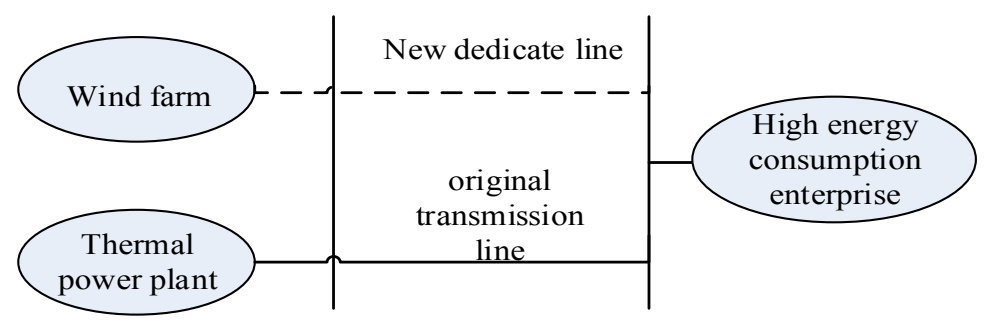

Fig.9. Dedicated power line solution

Optimize Allocation of Energy Storage Capacity. "Source-load" interaction sets a great requirement on response capability of load. Generally, we must renovate and upgrade the existing production equipment and process craft of high-energy consumptive enterprises, then they may meet response demand to overcome fluctuation and randomness of new energy output. If necessary, we should allocate energy storage system with certain capacity to some extent. Under the premise of this constraint, which energy storage system start to work only when both conventional generators and high-energy loads can't meet peak-shaving requirements, allocated capacity of energy storage system can be significantly reduced, and disposable equipment investment and cost of O\&M management can be reduced too. If setting reasonable peak-valley price, energy storage system operators will have a significant benefits.

\section{Conclusions and Prospect}

New energy power consumption through local high-energy loads is a systematic project. It is not only to solve problems from technical standpoint, but also involves high-energy consumptive enterprises, generators, grid corporations and government and other entities. Take into account of engineering practice, it is recommended to promote the work from following aspects:

(1) Automation degree of high-energy consumptive enterprises is generally low, so existing production equipment, process crafts, management systems and personnel skills are difficult to adapt new energy consumption. Through necessary technical innovation and integration will make production processes adopt to fluctuations and randomness of new energy. Continuously improve automation degree in production process and upgrade the level of intelligence adjustment will provide high-energy loads with ability to couple with output of new energy and conventional generators deeply, then automatic adjustment and optimization may be realized.

(2) It is necessary to improve predictive accuracy of wind power output or maintain prediction error within a certain range. Output characteristics of wind farm in Hexi area should be deeply researched. Adjustable capacity, adjust speed and other performances like this of high-energy loads should be take into consideration, as well as peak-shaving capacity of conventional generators, then calculation and analysis on influence of power supply reliability and safety margins under "source-load" interaction need take into consideration. We may allocate optimal capacity of energy storage to enhance interactive ability if necessary.

(3) Fluctuation of wind farm output would be stabilized within an acceptable range.

(4) Release policies relevant to price of new energy power consumption as soon as possible, and encourage enterprises participating in demand response actively by means of economic incentives. Based on regional economic and social development characteristics, rational plan layout of high-energy consumptive industry in Hexi area, in order to upgrade local adjustable capacity of power load.

\section{Acknowledgements}

We are particularly grateful to Gansu provincial electric power research institute, Jinchang electric power company, Wuwei electric power company and Baiyin electric power company for support. 


\section{References}

[1] D. Westermann and A. John, "Demand matching wind power generation with wide-area measurement and demand-side management," IEEE Trans. Energy Conversion, vol. 22, no. 1, pp. 145-149, 2007.

[2] MA Lindong, GE Zhiping, ZHANG Shicai et al. Active Peaking Technology Based on High Energy-consumption Enterprise Participating in Wind Power Accomodation in Power Grid[J]. Electric Power Construction Vo 1.34 (No.10): 102-106.

[3] National Science and Technology Support Program. Feasibility study report on key technologies about coordinating control of "source-grid-load" in large scale renewable energy base, 2014.

[4] State Grid Technology Program. Feasibility study report on key technologies about coordinating control of "load-grid-source" to save energy, 2013.

[5] LIU Cong, LIU Wenying, WANG Weizhou, etal. A Quantitative Method to Pre-Evaluate Power Grid's Capability of Accommodation for Wind/Photovoltaic Power Under Participation of High-energy loads [J]. Power System Technology, vol.39 (No.1): 223-229.

[6] LIU Wenying, WEN Jing, XIE Chang, etal. Multi-objective Optimal Method Considering wind Power Accommodation Based on Source-load Coordination [J]. Proceedings of the CSEE, Vol.35 (No.5):1079-1088.

[7] ZHANG Yan-xia, DONG Yong-ping, WANG Hong. The New Energy Peaking Feasibility Analysis with the Load Participation in the Electricity [J]. New Energy, (1): 61-63.

[8] ZHOU Qiang, WANG Ningbo, HE Shi'en, etal. Analysis on Photoelectric Development in Gansu and Countermeasures of the Power Grid Company [J]. Power Grid and Clean Energy, Vol.30 (No.4):60-67.

[9] MA Xiaodi. Study on the Acceptance Capacity of Wind Power under the Grid Peaking Constraints [D]. Beijing Jiaotong University, Beijing, 2014.

[10]GU Weidong. Non-grid Wind Power's Strategic Significance and Means to Ultra Large-Scale Wind Power Use [J]. Shanghai Energy Conservation,2010 (No.5):8-11.

[11]CEN Hai-tang, ZOU Wen-wu. The Application of Non-grid-connected Wind Power in Inner Mongolia, Renewable Energy Resources, Vol,28 (No.5): 147-149. 